\title{
Okul öncesi dönemde güncel bir ebeveyn davranışı: Sharenting
}

\author{
A current parent behavior in preschool: Sharenting
}

\begin{abstract}
Makale Geçmişi
Geliş : 15 Ağustos 2019

Düzeltme : 11 Subat 2020

Kabul : 16 Mart 2020
\end{abstract}

\section{Makale Türü}

Araștırma Makalesi

\begin{abstract}
Article History
Received : 15 August 2019

Revised : 11 February 2020

Accepted : 16 March 2020
\end{abstract}

Article Type

Research Article
Sebahaddin Aslan ${ }^{1}$, Emine Durmuş ${ }^{2}$

Öz: Bu çalıșmanın konusunu, ebeveynlerin çocuklarına ait fotoğraf ve bilgileri sosyal medyada paylaşmasına (sharenting) ilişkin tutumları oluşturmaktadır. Bu çalışmada, çocuğu anaokuluna devam eden annelerin, sosyal medyada çocuğu ile ilgili bilgi paylaşma tutumları incelenmiștir. Annelerin daha çok hangi platformlarda bilgi paylaştıkları, bilgileri ne sıklıkta paylaştıkları, paylaşım yaptıkları durumlar ve paylaşma gerekçeleri incelenmiştir. Araştırma 4-6 yaş aralığında çocuğu olan ve çocuğu anaokuluna devam eden 401 anne ile gerçekleştirilmiştir. Sonuçlar yüksek oranda $(\% 84,3)$ annelerin sosyal medyada, çocuklarıyla ilgili bilgi paylaştığını göstermiştir. Annelerin \%84.3'ünün sosyal medyada çocukları ile ilgili bilgi paylaştı̆̆ belirlenmiştir. Annelerin yaklaşık yarısı (\%48,1)'i bilgi ve fotoğraf paylaşmakta sakınca görmemektedir. Daha az sayıda anne (\%14) bilgi ve fotoğraf paylaşmayı doğru bulmadığını belirtmiştir. Ayrıca annelerin \%1.2'si bilgi ve fotoğraf paylaşmanın suç olduğunu düşündüğünü belirtmektedir. Paylaşımlar yaygın olarak kullanılan sosyal medya platformları olan Facebook ve İnstagramdan ziyade Whatsapp-durum'unda (\% 52,9) yapılmaktadır. Çocukları iki yaşına gelmeden onlarla ilgili bilgi ve fotoğraf paylaşan annelerin oranı \%46,1 olarak bulunmuştur. Yapılan paylaşımların \% $\% 4,4$ ü özel günlerle ilgilidir. Paylaşımlar, anı biriktirmek $(\% 45,8)$, paylaşımların beğenilmesinden mutlu olmak $(\% 22,2)$ gibi gerekçelerle paylaşmaktadırlar.

Anahtar Kelimeler: Sharenting, Sosyal medya, Okul öncesi, Ebeveynler

Abstract: The subject of this study is that parents' sharing attitudes of the photos and the informations of their children on social media. In this study, mothers', whose children attends to the kindergarten, sharing attitudes of the information about their children on social media was investigated. Answers are sought to following questions: Which platforms are used more for sharing, how often they share, in which situations they share and for what reasons they share? The study was carried out with 401 mothers whose children are in between the ages of 4-6 and attending kindergarten. The results showed that $84,3 \%$ of mothers share information about their children on social media. Almost half of the mothers $(48,1 \%)$ sees no harm in sharing information and photos. Less mothers $(14 \%)$ stated that they disapproves of shareing the information and photos of their children. Additionally, $1,2 \%$ of mothers think that it is crime to share their children's information and photos on social media. Shares are done on Whatsapp-status $(52,9 \%)$ rather than on commonly used social media platforms such as Facebook and Instagram. Mothers (46,1\%) share information and photographs about their children before they reach to their two. $47.4 \%$ of the sharings are related to the special days. Sharings are done in order to collect memories $(45,8 \%)$ and to be happy about the likes they get $(22.2 \%)$.

Keywords: Sharenting, Social Media, Pre-school, Parents

\footnotetext{
${ }^{1}$ İnönü Üniversitesi, Eğitim Bilimleri Ensitüsü, Psikolojik Danıșma ve Rehberlik Programı Yüksek Lisans Öğrencisi, sebahaddinaslan.pdr@gmail.com ORCID: http://orcid.org/0000-0002-9479-4889

${ }^{2}$ İnönü Üniversitesi, Eğitim Fakültesi, Psikolojik Danışma ve Rehberlik ABD Öğretim Üyesi, emine.durmus@inonu.edu.tr, ORCID:

http://orcid.org/0000-0002-7102-5833
} 


\section{SUMMARY}

\section{Introduction}

With the increase of the ways accessing to the internet, the usage of social networking sites have increased as well. Today, it is possible to see users of all ages on social networking sites. Users have these social media accounts for many different purposes such as playing games, communicating, sharing information and photographs (Allen, Ryan, Gray, Mclnerney and Waters, 2014). As for, parents use their social media accounts to share the photos of their children.

Parents' uncontrolled actions on social media put both children and themselves at risk. With the widespread of social media usage, parents share the photos of the activities that they do with their children. Sometimes, the privacy of the children can be invaded via posts. Parents sharing the content about their children is called ‘sharenting' (Blom-Ross, Livingstone, 2017; Collins Dictionary, 2019).

When risks of sharenting is researched, factors such as the usage of the shared photos by third parties (Minkus, Liu and Ross, 2015), the invasion of the child's privacy (Davis, 2015), and the negative effects on personality development (Davidson-Wall, 2018) appears to be the important issues. Even though there have been legislative regulations regarding to the protection of children from the risks of these kind of posts in USA (COPPA, 1998), in Turkey, there are no legislative regulations yet (Çimke, Gürkan ve Polat, 2018) .

In this research, social media posts of mothers whose children attend to kindergarten is studied in different aspects such as; whether they post about their children or not, the frequency of the posts, age of the children when they did their first post, who else posts the informations other than the mother, which social media platforms they use, the occasions they post on and the reason why they post. Preschool period is a period when the child is dependent on his parents. Because of the children were vulnerable in this period, the preschool period was handled in the research.

\section{Method}

This research is a descriptive, survey analysis which studies the social media posts of mothers who have 4,5 and 6 year old children who is attending a preschool institution, from multiple directions. The study group is chosen by convenient sampling method. The study is conducted with 401 mothers who have 4, 5 and 6 year old children in kindergarten. The data was obtained by researchers with data collection form in order to present sharenting lives of mothers whose children attend to kindergarten

\section{Results}

Results show high rates $(84,3 \%)$ of mothers who share information about their children on social media. Besides mothers, family members are second in sharing (41,9\%). Half of the mothers (48,1\%) see no harm in sharing and a big group of mothers $(36,7 \%)$ share even though they find the post inappropriate. Posts are shared on WhatsApp Status (52,9\%) instead of popular apps like Facebook or Instagram. Mothers share 
information and photos of their children before they turn two (46,1\%). $70 \%$ of the kids have content on social media by the time they are four. Participants share in order to save photos and informations about special occasions $(47,4 \%)$, to save memories $(45,8 \%)$ and because likes make them happy $(22,2 \%)$. Few mothers state that they think posting is wrong $(14 \%)$ or is a crime $(1,2 \%)$.

\section{Conclusion and Discussion}

The results show almost $85 \%$ of mothers post information and photos of their children before the age of six. The popularity of smart phones and being able to take photos anytime make posting photos on social media easy and inevitable (Wagner and Gasche, 2018)

Mothers who think it's a crime to share $(1,2 \%)$ and mothers who disapprove sharing information (14\%) constitute a small percentage (15\%). According to this information, most of the mothers don't think sharing information on social media is wrong and a crime.

Participants stated that they 'rarely' share their children's photos (55,9\%). These results show even though the percentage of sharing is high, the frequency of sharing is low. A research conducted in Germany and Austria shows that most of the participants share at least once a month (Wagner and Gasche, 2018). Different researches in this field show the frequency is higher. Maraşl1 et al. (2016) state that post-sharing percentage in profiles studied throughout three months is high. Low posting rate that is found in this research, can be explained as limitation of this research because data wasn't obtained directly from mothers' social media accounts.

Mothers share information and photos usually on special occasions such as birthdays or first tooth parties, vacations or school related activities such as production, success, awards. Results show parents share information and photos about their children even though parents think that it is wrong. Some parents share photos even before birth. These datas show children are in serious risk in sharenting context. Children at that age can't possibly understand, approve or protect themselves from the context of these posts. Therefore, parents should have information about privacy policy of the sites where they share information about themselves or their children, and be careful not to post personal information of their kids (id no, date of birth) on social networks. They should consider the potential short and long term effects of these posts on their children.

Parents should consider the dangers of sharing personal information of their kids in public area. Seminars should done in kindergarten and elementary school for the parents about online rights of privacy since they need to know more about sharing posts about their kids on social media (Steinberg, 2016; Steinberg 2017). Psychological counselors who work on preschool education have great responsibility on this subject. Projects about sharenting risks can be planned for parents, family members, teachers and school staff. 


\section{GİRIŞ}

İnternet kullanım oranının artmasıyla birlikte sosyal medya kullanıcı sayısı da her geçen gün artmaktadır. Yaşları 6-15 yaş arası olan çocukların \%59'unun akıllı telefon, \%41'inin de sosyal medya kullandıkları (DigitalTalks, 2018) görülmektedir. Bu oranlar, sürekli yenilenen cep telefonu uygulamaları ile yalnızca genç ve yetişkinlerin değil, yaşları küçük çocukların da dijital dünyada kimliklere sahip olduğunu göstermektedir. "We are social Batı Asya Raporu” na (2019) göre Türkiye'de 59.36 milyon internet kullanıcıs1, 52 milyon aktif sosyal medya kullanıcısı, 44 milyon aktif mobil sosyal medya kullanıcısı vardır. Türkiye'de kullanıcıların günde ortalama 7 saat internet kullandıklarını ve bu 7 saatin yaklaşık 3 saatini sosyal medyada geçirdikleri görülmektedir. İnternette geçirilen vaktin neredeyse yarısı sosyal medya platformlarında geçmektedir. Bireyler, oyun oynamak, paylaşımda bulunmak, vakit geçirmek, iletişim kurmak ve resim göndermek gibi birçok farklı türde eğlence ve sosyal etkinlik yapmak için sosyal medya sitelerini ziyaret etmektedirler (Allen, Ryan, Gray, Mclnerney ve Waters, 2014).

Çocuk, genç, yetişkin ya da ebeveynlerin internet ve sosyal medya kullanım gerekçeleri farklılık göstermektedir İnternet ortam1, web sayfaları, Facebook, Instagram gibi sosyal platformlar ebeveynlere çocukları ile ilgili yeni ve zorlu problemlerle baş etmek için, bilgi ve destek hizmeti de sağlamaktadırlar. İngiltere'de 2017 yllının sonunda 0-17 yaş arası çocuklara sahip 2032 ebeveyn ile yapılan bir araştırmada ebeveynlere 'geçtiğimiz ayı düşündügünüzde interneti çoğunuza ne yapmak için kullandınız’ diye sorulmuş ve katılımcıların \%51’i çocuğumun öğrenmesine yardım edecek bilgileri araştırmak seçeneğini işaretlemiştir (Livingstone, Blum-Ross, Pavlick ve Olafsson, 2018). $\mathrm{Bu}$ bilgileri edinme sürecinde ebeveynler çocuklarına ilişkin içerikleri sosyal medyada paylaşma durumunda kalmaktadır. Bu paylaşımlar bazen çocuğun fotoğrafları, video görüntüleri olduğu gibi bazen de doğum tarihi, kimlik numarası gibi özel bilgileri de içermektedir. Bu platformlar ebeveynlerin çocukları ve yaşantıları ile ilgili daha çok deneyim paylaşmalarına da firsat sunmaktadır. Sonuçta pek çok çocuk henüz yürümeye başlamadan önce sosyal medyada yaşamları hakkında birçok resim, bilgi ve içeriğe sahip olmaktadır (Brosh, 2016).

Anne babaların çocuklarının fotoğraflarını, haberlerini sosyal medya hesaplarında paylaşmasının literatürde ki tanımlamasi; sharenting. Bu kavram share (paylaşma) ve parent (anne-baba) kelimelerinin birleşiminden türetilmiş ve ebeveynlerin sosyal medyada çocukları hakkında düzenli olarak bilgi paylaşması şeklinde tanımlanmaktadır (Blom-Ross, Livingstone, 2017). Sharenting, Collins Dictionary tarafından "Çocukların haberlerini, resimlerini vb. paylaşmak için alışılmış sosyal medya kullanımı" olarak tanımlanmıştır (Sharenting: Collins Dictionary,2019). Paylaşımlar dijital ortamların büyük çoğunluğunda yapılabilir. Bu kavram, ebeveynlerin, çocuklanının resimlerini 
Sosyal A $\breve{g}$ Sitelerinde (SNS) paylaştı̆̆1 olgusuna atıfta bulunur. Her ortam ve durumda fotoğraf çekme kolaylığı, bu fotoğrafların sosyal medyada paylaşılmasını da kaçınılmaz yapmaktadır (Wagner ve Gasche, 2018).

Araştırmalar (Brosh, 2016; Davis ve diğerleri 2015) anne-babaların sosyal medya hesaplarında geçirdikleri zamanın bir kısmını çocuklarına ilişkin içerikleri paylaşmakla harcadıklarını göstermektedir. Danimarka'da yapılan bir araştırma bulgularına göre sharenting olgusunun ebeveynlik uygulamaları ile sıkı bir şekilde iç içe geçtiği görülmektedir. Ebeveynlerin 'iyi bir ebeveyn’ olma ve bunu duyurma gerekçesi ile "paylaşıp-paylaşmama" nın ikilemi arasında kaldıkları vurgulanmaktadır (Damkjaer, 2018).

Polonya'da yapılan bir diğer araştırmada, 8 yaş altı çocuğu olan 168 ebeveynin facebook hesabı incelenmiştir. Sonuçlara göre ebeveynlerin yaklaşık \% 40'1 çocuklarının 100'den fazla fotoğrafını yayınlamış ve bu 168 hesaptan \% 90,5’i çocuğun adından bahseden bir yorum yayınlamış ve \% 83,9’u da çocuğun doğum tarihini açık etmiştir. Katılımcıların \% 32,7’si bebek videolarını ve doğum sertifikası, anaokulu diploması gibi çocuğu ilgilendiren diğer belgeleri de paylaştıkları görülmüştür (Brosh,2016). Ebeveynlerin bu paylaşımları arasında, ultrason fotoğrafları gibi, bebek henüz dünyaya gelmeden elde edilen görüntüler de bulunmaktadır. Amerika Birleşik Devletleri'nde yapılan bir araştırmanın bulguları da bu sonucu desteklemektedir. Buna göre, çocukların büyük çoğunluğu (\%92) henüz iki yaşına gelmeden sosyal medyada bir tür varlığa sahip olmaktadırlar (Duggan, Lenhart, Lampe ve Ellison, 2015).

Estonya'da yaşları 9-13 arasında değişen 14 anne-çocuk çiftiyle yapılan çalışmada, sharenting davranışının hem anne hem de çocuk açısından nasıl algılandığı araştırılmışı̧ı. Araştırmaya göre bazı anneler Facebook'un fotoğraf ve bilgi paylaşmaya uygun olmadığını düşünmelerine rağmen paylaşım yapmaya devam ettiklerini belirtmişlerdir. Örneklem içerisindeki aileler çocuklarının sosyal medya hesaplarına ilişkin çocuklarına kurallar koymuş, fakat bu kurallara kendilerinin uymadıkları görülmüştür. Çocuklarla yapılan görüşmelerden çıkan sonuçlar çocukların, annelerinin başarıları hakkında paylaşımlardan memnun olduklarını hatta gurur duyduklarını fakat kendileriyle ilgili olumsuz imaj yaratabilecek paylaşımlardan da rahatsız olduklarını ortaya koymuştur (Lipu ve Siibak, 2019). Çocuklar olumsuz, çevrimiçi bir görüntü veya kimliğe değil, olumlu destekleyen içerikten daha çok hoşnut ve daha çok değer verdikleri görülmüştür. Çocuklar spora, okula ve hobilere katılımıyla ilgili olumlu içerik paylaşan ebeveynleri iyi olarak görmekle birlikte, ebeveynlerin kendileri hakkında mahremiyetlerini ihlal eden bilgileri de paylaşmalarını olumsuz olarak algilamaktadirlar (Moser, Chen ve Schoenebeck, 2017). "Ebeveynler, Gizlilik ve Teknoloji 
Kullanımı (Parents, Privacy \& Technology Use)" raporuna göre ise ebeveynlerin \%19’u çocuklarıla ilgili "çocuğun utanç verici bulduğu" çevrimiçi bir şey yayınladıklarını, çocuğun ebeveynden paylaşımı kaldırmasını istediklerini veya gelecekte paylaşımın utanç verici olabileceklerini belirtmişlerdir (Family Online Safety Institute, 2015, s.22).

Annelerin sosyal medyada çocuklarına ilişkin paylaşımları ile babaların paylaşımları hem içerik (Ammari, Kumar, Lampe ve Schoenebeck, 2015; Choi ve Lewallen, 2018) hem de s1klık (Davis ve Diğerleri, 2015; Wagner ve Gasche, 2018; Lipu ve Siibak, 2019) bakımından birbirinden farklilıklar göstermektedir. Annelerin babalara göre sayı olarak daha fazla paylaşım yaptıkları, babaların ise içerik yönünden annelere göre daha temkinli ve sınırlı davrandıkları söylenebilir.

Türkiye'deki araştırma sonuçları incelendiğinde, 200 Facebook kullanıcı hesabının geriye dönük bir yıllık paylaşımlarının analiz edildiği bir araştırmada kullanıcıların \%28’inde çocukların iç çamaşırlı ya da mayolu fotoğraflarının paylaşıldığı görülmüştür (Özaslan, Gültekin Akduman ve Aydoğan, 2018a). Bu paylaşımlar için annelerin çocuklarından izin almadıkları ve paylaşımları onaylamamalarına rağmen sürdürdükleri bilinmektedir (Özaslan, Gültekin Akduman ve Aydoğan, 2018b). Facebook paylaşımlarının 3 ay boyunca analiz edildiği bir diğer araştırmada ise katılımcıların \%81,4’ü doğum günleri, mezuniyet ve yılsonu gösterileri gibi özel günleri paylaştıkları görülmüştür. Katılımcıların yüzde 37,2'si çocukları hakkında bilgi paylaştığında mutlu olduklarını ve yüzde 44,39'u çocuklarını Facebook dışındaki diğer sosyal paylaşım sitelerinde paylaştıklarını belirtmişlerdir (Maraşlı, Sühendan, Y1lmaztürk ve Cok, 2016).

\section{Sharenting ve Hukuki Boyut}

Aileler sosyal medyada birçok farklı şekilde paylaşımda bulunurlar. Bu çevrimiçi paylaşımlar bazı faydaları olmasıyla birlikte, yasal ve güvenlik riskleri de barındırmaktadır (Steinberg, 2016). Ebeveynler çocukların fotoğraflarını sosyal paylaşım ağlarına paylaştıklarında, akıllarından onlara zarar vermek geçmeyebilir. Ancak bu paylaşımlar çocuklar için riskler barındırabilir. Minkus, Liu ve Ross (2015) ebeveynlerin çocukları hakkında yayınladıkları fotoğraf ve verileri, veri aracılarının başka amaçlar için kullanabileceklerinin altını çizmiştir. Çocuk fotoğraflarının açık paylaşımlarının, çocuğa yönelik suçlar bağlamında risk yaratabileceği ifade edilmektedir.

Çocuklarla ilgili riskleri azaltmak amacıyla, ABD de, Çocukların Çevrimiçi Gizlilik Koruma Yasası (Children's Online Privacy Protection Act-COPPA), 1998 yllinda yürürlüğe girmiş ve operatörlerin yani sosyal paylaşım ağ yöneticilerinin, web sayfası adminlerinin dolayısıyla verilere çok kolay ulaşabilecek kişilerin, 13 yaş altı çocuklara ilişkin verileri izinsiz alıp kullanması yasaklanmıştır. Bu 
yasa sayesinde çocuk fotoğraf ve verilerinin kullanımı için ebeveyn izni şartı getirilmesine rağmen ebeveynler için bir düzenleme yoktur.

Bazı sharenting vakalarının hukuki sonuçlarını medyaya yansımıştır. İtalya'da yaşanmış 16 yaşındaki bir çocuğun, annesinin kendisinin fotoğraflarını rızası olmaksızın paylaşmasına ilişkin açtığı davada hem annenin paylaşımları silmesine hem de 10 bin Euro tazminat ödemesine hükmetmiştir (Gültekin, 2018). Fransa'da çıkan yasada anne-babalar çocuklarına ait fotoğrafları sosyal medyaya yüklemesinden sorumlu tutulmuş ve çocuklara büyüdüklerinde ilgili paylaşımlar nedeniyle annebabalarına dava açma hakkı verilmiştir (Chazan, 2016).

Türkiye'de Avrupa veya Amerika Birleşik Devletlerinde olduğu gibi dijital ortamda çocukların mahremiyetini korumaya yönelik özel bir yasa veya tasarı 2019 y1lı itibarı ile mevcut değildir. Buna karşı1ık Türkiye'nin taraf olduğu uluslararası sözleşmeler (Çocuk Haklarına dair Birleşmiş Milletler Sözleşmesi (CHS) ve Avrupa İnsan Hakları Sözleşmesi) ve Türk Ceza Kanununda ki bazı maddeler, doğrudan hükümler içermeseler de ebeveyn görevlerini ifade etmeleri ve çocuk mahremiyetine nokta vurgular yapmaları, sharenting olgusu ile birlikte yorumlanabilir (Akdi, 2016; Kaya ve Kaya, 2018). Çocuk hakları sözleşmesi 19. Maddesi taraf olan devletlere çocuk haklarının korunması hususunda ciddi sorumluluklar yüklemiş olsa da ülkemizde bu paylaşımları engelleyecek ya da yaptırım uygulayacak yeterli yasalar bulunmamaktadır (Çimke, Gürkan ve Polat, 2018).

Okul öncesi dönem çocuğun hem anne-babasına bağımlı olduğu, hem de ilk kez okul ortamına adım attığı dönemdir. Anaokulları çocukların ev dışında ilk kez ürün ortaya koydukları, başarı ya da performans sergiledikleri ortamlar olmaları nedeni ile aileler tarafindan önemsenmektedirler. Anaokullarında, çocukların belirli gün ve haftalarda yaptıkları etkinlikler veya yılsonu gösterilerde ortaya çıkardıkları ürün ile fotoğraf çektirilmeleri yaygın bir alıskanlıktır. Bu ortamlarda çektirilen bu fotoğraflar zaman zaman öğretmenler ya da okul yönetimi tarafindan sosyal platformlarda paylaşılmaktadır. Ebeveynler, çocuklarını bu fotoğrafların çekimi sırasında ön sıralarda olmaları noktasında teşvik etmekte, anaokulu öğretmenlerinden bu fotoğrafları talep etmekte ve sosyal medya hesaplarında paylaşmaktadırlar. Sharentingin daha çok anneler tarafindan yapılmasından (Davis ve diğerleri, 2015; Lipu ve Siibak, 2019) hareketle bu araştırma okulöncesi dönemde öğrenim gören çocuğa sahip anneler ile gerçekleştirilmiştir.

$\mathrm{Bu}$ çalışmanın amacı, çocukları anaokuluna devam eden annelerin sosyal medya ortamında çocuklarına ilişkin bilgi paylaşımları (paylaşım yapıp yapmadığı, paylaşım sıklığı, paylaşım yaptıkları durumlar ve platformlar, paylaşım yapmayı onaylama ve anne dışında kimlerin paylaşım yaptığı) ve 
bu paylaşımların gerekçelerini çok yönlü incelemektir. Bu bağlamda araştırma soruları şöyle düzenlenmiştir;

1. Annelerin sosyal medya ortamında çocuklarıyla ilgili paylaşımları nasıldır?

2. Annelerin sosyal medya ortamında çocuklarıyla ilgili paylaşımda bulunma gerekçeleri nelerdir?

\section{YÖNTEM}

\section{Araştırma Modeli}

$\mathrm{Bu}$ araştırma, 4,5 ve 6 yaşında bir okul öncesi kuruma devam eden çocuğu olan annelerin çocuklarıyla ilgili sosyal medya paylaşımlarını çok yönlü inceleyen tarama türünde betimsel bir çalışmadır.

\section{Çalışma Grubu}

$\mathrm{Bu}$ araştırmanın çalışma grubunu, Türkiye'nin Gaziantep, Osmaniye ve Elazı̆̆ illerine bağlı anaokullarına devam eden çocukların anneleri oluşturmaktadır. Çalışma grubu kolay ulaşılabilir örnekleme yöntemi ile seçilmiştir. Bu çalışma, yaşları 4-5 ve 6 olan ve anaokuluna devam eden çocuğa sahip 401 anne ile gerçekleştirilmiştir. Araştırma çalışma grubunun demografik özellikleri Tablo-1'de verilmiştir.

Tablo 1. Katılımcilara ait demografik bilgiler

\begin{tabular}{llcc}
\hline & & $\mathbf{N}$ & $\mathbf{\%}$ \\
\hline Annelerin & $20-29$ & 126 & 31,42 \\
Yaş1 & $30-39$ & 234 & 58,35 \\
& 40 ve üstü & 41 & 10,22 \\
& & & \\
Öğrenim Düzeyi & İlkokul & 72 & 17,95 \\
& Ortaokul & 75 & 18,70 \\
& Lise & 138 & 34,41 \\
& Lisans/Lisansüstü & 116 & 28,92 \\
\hline Toplam & & 401 & 100.00 \\
\hline
\end{tabular}

Tablo-1 katılımcıların çoğunluğunun 30-39 yaş aralı̆̆ında $(N=234, \% 58)$ ve lise mezunu $(N=138$, \%34) olduğunu göstermektedir. 


\section{Veri Toplama Arac1:}

Veriler, çocuğu anaokuluna devam eden annelerin sharenting yaşantılarını ortaya koymak amacıyla yazarlar tarafindan hazırlanan anket formu ile elde edilmiştir. Anket formu hazırlama sürecinde öncelikle alan yazın taranmış, bu konuda sınırlı sayıda yurt içi ve yurt dışı araştırma incelenmiştir. İncelenen çalışmalarda (Davis ve Diğerleri, 2015; Maraşlı, Sühendan, Yılmaztürk ve Cok, 2016; Lipu ve Siibak, 2019) kullanılan ölçme aracı, anket ve bilgi toplama formlarından yararlanılarak bu çalışmada kullanılan anket için bir madde havuzu oluşturulmuştur. Ek olarak, çocuğu anaokuluna devam eden ve çocuğu ile ilgili sosyal medya paylaşımları olan sekiz anne ile paylaşımları konusunda görüşme yapılmıştır. Bu görüşmede annelere "paylaşım yaptıkları durumlar", "çocuklarına yönelik paylaşım yapma gerekçeleri”, "paylaşımları annelerden başka kimlerin yaptığı" gibi konu başlıkları altında sorular yöneltilmiştir. Annelerle yapılan bu görüşmeler analiz edilerek, madde havuzuna eklenmiştir. Madde havuzundan yer alan maddeler yazarlar tarafindan düzenlenerek bir anket formuna dönüştürülmüş ve alan uzmanlarının görüşüne sunulmuştur. Alan uzmanı olarak, Psikolojik danışma ve rehberlik anabilim dalında görev yapan üç öğretim üyesi, iki doktora ve iki yüksek lisans öğrenci ve bir anaokulunda görev yapan Psikolojik Danışmanın görüşleri alınmıştır. $\mathrm{Bu}$ değerlendirmeler doğrultusunda bilgi toplama formu yeniden düzenlenmiştir. Formun dil ve ifade açısından anlaşılırlığını test etmek amacıyla, 6 anne ile pilot uygulama yapılmıştır.

Toplamda 12 maddeden oluşan anket formunun ilk bölümünde annelerin yaş, öğrenim gibi sosyodemografik bilgilerine yer verilmiştir. Anketin ikinci bölümünde annelerin çocuklarıyla ilgili sosyal medya paylaşımlarını belirlemeyi amaçlayan ifadelere yer verilmiştir. Anket formunda katılımcıları sınırlamamak amacıyla bazı ifadelerde annelere birden fazla seçenek işaretlemelerine olanak tanınmıştır. Bu bilgi hem form üzerinde katılımcılar için, hem de bulgularda tablo altlarında belirtilmiştir. Veri toplama aracının doldurulması toplam 15 dakika sürmektedir.

Veriler, hazırlanan anketler yoluyla, Gaziantep, Osmaniye ve Elazı̆̆ illerinde toplanmıştır. Çalışmanın katılımcıları, bu illere bağlı Anaokullarına devam eden çocukların annelerinden oluştuğundan, okul yöneticilerinden izin alındıktan sonra, çalışmaya yalnızca gönüllü anneler dahil edilmiştir. Verilerin toplanması sırasında anaokullarında görev yapan Psikolojik Danışmanlar ve Okul Öncesi Öğretmenlerinden destek alınmakla birlikte, tüm veriler araştırmacılar tarafindan yüz yüze toplanmıştır.

\section{Verilerin Analizi:}

Araştırma verileri için, farklı illerde toplam 424 anneye ulaşılmışır. Anneler tarafından doldurulan formlardan 23’ü eksik ve hatalı veri nedeniyle elenmiştir. Analizler toplam 401 anket formundan 
elde edilen veriler üzerinden yapılmıştır. Veriler, SPSS ortamında analiz edilerek, bulgular frekans ve yüzdelik oranlarılya, tablolar halinde sunulmuştur. Tablolarda tek seçeneğin işaretlenebileceği maddelerde toplam veri sayısı katılımcı sayısına $(\mathrm{N}=401)$ eşit olarak hesaplanırken, birden fazla seçeneğin işaretlenebileceği maddelerde toplam veri sayısı, işaretleme sayısına eşit olarak hesaplanmıştır.

\section{BULGULAR}

Bu bölümde anaokuluna devam eden çocukların annelerinin çocuklarıla ilgili sosyal medyada bilgi paylaşmalarıyla ilgili frekans ve yüzdelik oranları tablolar halinde sunulmuştur.

Tablo 2. Annelerin çocuklarıyla ilgili sosyal medya ortamında paylaşımlarının dağılımı

\begin{tabular}{|c|c|c|c|}
\hline Annelerin & & $\mathrm{N}$ & Yüzde \\
\hline \multirow{4}{*}{$\begin{array}{l}\text { Çocuğuyla ilgili bilgi paylaşma } \\
\text { tutumu }\end{array}$} & Doğru Buluyorum/Paylaşıyorum & 193 & 48,1 \\
\hline & Yanlış Buluyorum/Paylaşıyorum & 147 & 36,7 \\
\hline & Yanlış Buluyorum / Paylaşmıyorum & 56 & 14,0 \\
\hline & Suç Olduğunu Düşünüyorum & 5 & 1,2 \\
\hline \multirow[t]{5}{*}{ Bilgi Paylaşım Sıklığ1 } & Her Zaman Paylaşırım & 27 & 6,7 \\
\hline & Sık Paylaşırım & 83 & 20,7 \\
\hline & Nadiren Paylaşırım & 224 & 55,9 \\
\hline & Hiç Paylaşmam & 67 & 16,7 \\
\hline & Whatsapp Durum & 276 & 52,9 \\
\hline \multirow{4}{*}{$\begin{array}{l}\text { Paylaştıkları Sosyal medya } \\
\text { platformları* }\end{array}$} & İnstagram & 97 & 18,6 \\
\hline & Facebook & 73 & 14.0 \\
\hline & Twitter & 4 & 0.8 \\
\hline & Paylaşmam & 72 & 13.8 \\
\hline İlk Bilgi Paylaştıklarında & $0-2$ yaşında & 180 & 44,9 \\
\hline \multirow[t]{4}{*}{ Çocuğun Yaşı } & 3-4 yaşında & 101 & 25,2 \\
\hline & 5-6 yaşında & 57 & 14,2 \\
\hline & Hiç paylaşmadım & 63 & 15,7 \\
\hline & Okul/Öğretmen & 30 & 7,5 \\
\hline \multirow[t]{3}{*}{ Anne Dışında Bilgi paylaşanlar } & Arkadaş çevresi & 18 & 4,5 \\
\hline & Diğger Aile üyeleri & 168 & 41,9 \\
\hline & Kimse Paylaşmaz & 185 & 46,1 \\
\hline
\end{tabular}

Tablo-2 incelendiğinde çalışmaya katılan annelerin yarısına yakını \%48,1 (N=193) sosyal medyada çocuğu ile ilgili bilgi paylaşmayı doğru bulduğunu ve paylaştıklarını ifade etmişlerdir. Büyük oranda anne grubu \%36,7 ( $\mathrm{N}=147)$ bilgi paylaşmayı yanlış bulduklarını ama çocuklarıyla ilgili paylaşım yaptıklarını belirtmişlerdir. Çocukla ilgili paylaşımı yanlış bulup paylaşmayan ve doğru bulup paylaşan annelerin oranı çıkarıldığında, yüksek oranda annenin bu konuda kafasının karışık olduğu görülmektedir.

Bilgi paylaşım sıklığ1 bakımından çocuğu anaokuluna devam eden annelerin \%16,7'si (N=67) internet ortamında çocuğu ile ilgili hiçbir şekilde paylaşımda bulunmadıklarını ifade etmişlerdir. Buna karşılık annelerin \%83,7'sinin $(\mathrm{N}=334)$ sosyal medyada çocuklarına ilişkin bilgi paylaşımında 
bulunduklarını belirtmişlerdir. Annelerin yarısından fazlası \% 55,9 (N=224) nadiren bilgi paylaştıklarını ifade ederken, \% 20,7’si $(\mathrm{N}=83)$ sık paylaştığını belirtmişlerdir. Anneler paylaşımları çoğunlukla $(\% 52,9)$ Whatsapp-Durum uygulamasında gerçekleştirdiklerini ifade etmişlerdir. Bunu oran1, \% 18,6 oranında İnstagram ve \%14 oranında Facebook’un takip ettiği görülmektedir. Annelerin ilk paylaşımı yaptıkları sırada çocuğun yaşı ile ilgili sonuç değerlendirildiğinde, annelerin \%44,9'unun ( $\mathrm{N}=180)$ çocuk henüz iki yaşına gelmediğinde paylaşım yaptıklarını göstermektedir. Annelerin \%25,2'si (N=101) çocukları 3-4 yaşlarında iken ilk kez bilgi paylaştıklarını, \%14’ü ise, 56 yaşlarında paylaştıklarını belirtmişlerdir. Okulöncesine devam eden çocuğu olan annelerin çoğunluğu \% 46,1 (f=185) kendileri dışında başka kimsenin çocuğu ile ilgili sosyal medya paylaşımı yapmadığını ifade etmişlerdir. Bu bulgu, bir bakıma çocukla ilgili sosyal medya paylaşımlarının neredeyse yarısının anneler tarafindan yapıldığını da göstermektedir. Anneler dışında diğer aile üyeleri (eş, büyük ebeveynler, hala teyze vb)'nin paylaşım oranın da en az anneler kadar yüksek olduğu görülmektedir (\% 41,9, N=168). Anneden başka baba ve büyük ebeveyn, hala teyze gibi diğer aile bireylerinin de paylaştıkları ortaya çıkmaktadır. Okul ve öğretmen $(\% 7,5)$ ve arkadaşların $(\% 4,5)$ çok düşük oranlarda paylaştıkları görülmektedir.

Katılımcı annelerin hangi durumda çocuklarıla ilgili sosyal medyada paylaşım yaptıkları ve gerekçelerine ilişkin sonuçlar Tablo 3'de özetlenmiştir.

Tablo 3. Annelerin paylaştıkları durumlar ve gerekçelerinin dağılımı

\begin{tabular}{lrr}
\hline *Annelerin Paylaşım Yaptıkları Durum ve Gerekçeler & $\mathrm{N}$ & $\%$ \\
\hline Annelerin Sosyal Medyada Çocuklarılla İlgili Paylaştıkları Durumlar & & \\
Tatil / seyahat anları & 77 & 13,2 \\
Okul yaşantıları (etkinlik, başarı, ödül vb) & $\mathbf{1 1 5}$ & $\mathbf{1 9 , 8}$ \\
Ev yaşantıları (oyunlar, ilk yaptıkları vb.) & 54 & 9,3 \\
Özel günler (doğum günü, diş partisi gibi) & $\mathbf{2 7 6}$ & $\mathbf{4 7 , 4}$ \\
Paylaşmıyorum & 60 & 10,3 \\
TOPLAM & 582 & 100 \\
& & \\
Annelerin Sosyal Medyada Çocuklarıyla İlgili Paylaşımlarının Gerekçeleri & & \\
Herkes paylaşıor, uyum sağlıyorum & 19 & 3,7 \\
Paylaşımların beğenilmesi mutlu ediyor & $\mathbf{1 1 5}$ & $\mathbf{2 2 , 2}$ \\
İlgili ebeveyn olduğumu gösteriyorum & 14 & 2,7 \\
Hatıra olsun diye paylaşıorum. & $\mathbf{2 3 7}$ & $\mathbf{4 5 , 8}$ \\
Okulundaki başarılarını duyurmaktan keyif alıyorum & 73 & 14,1 \\
Paylaşmıyorum & 59 & 11,4 \\
TOPLAM & 517 & 100 \\
\hline
\end{tabular}

* Birden fazla seçenek işaretlenmiştir

Tablo-3 incelendiğinde; annelerin yarısına yakının (\% 47,4, f=376) çocuklarının doğum günü, diş partisi, mezuniyet vb özel günlere dair paylaşımlar yaptıklarını ifade etmişlerdir. Annelerin 
ifadelerinin \% 19,8'inde çocuklarının etkinlik, performans, başarı, ödül gibi okul yaşantılarıyla ilgili paylaşım yaptıkları yer almaktadır.

Çalışmanın bu bölümünde, çocuğu anaokuluna devam eden annelerin çocuğu ile ilgili sosyal medyadan neden bilgi-fotoğraf paylaştıklarına yönelik işaretlemeleri değerlendirilmiştir. Sonuçlar göstermiştir ki, annelerin büyük çoğunluğu \% 45,8 (f=237) oranında, hatıra olsun diye paylaştıklarını ifade etmişlerdir. İkinci sırada, çocuğu ile ilgili paylaşımların verdiği mutluluğu yaşamak için $(\% 22,2)$ paylaştıkları görülmektedir. Annelerin çocuklarının okul başarılarını duyurmaktan keyif almaları $(\% 14,1)$ da bir diğer paylaşım nedeni olarak işaretlenmiştir. Oranları düşük olmakla birlikte, \% 3,7 oranında, herkes paylaştığı için paylaştıkları ve $\% 2,7$ oranında ise, ilgili ebeveyn olduğunu göstermek için paylaştıkları ifade edilmiştir. Bu tabloda da \% 10 ile \% 11 oranında anne, hiçbir durum ve gerekçe ile paylaşımda bulunmadıklarını ifade etmişlerdir.

Araştırmada Tablo-2 de \%36,7 oranında, anneler paylaşım yapmayı onaylamadıkları halde paylaştıklarını ifade etmelerine rağmen, Tablo-3'de herkes paylaşıyor, uyum sağlıyorum maddesi \% 3,7 gibi düşük oranda işaretlenmiştir. Bu bulgu, bu konuda annelerin kafalarının karışık olduğu ve ikilem yaşadıkları yönünde değerlendirilebilir.

\section{SONUÇ VE TARTIŞMA}

$\mathrm{Bu}$ araştırmanın sonuçları iki temel başlık altında incelenmiştir. Birincisi annelerin çocuklarının sosyal medya ortamında bilgilerini paylaşma durumları ve ikincisi bu duruma ilişkin gerekçeleridir.

Araştırma araştırmanın birinci sorusu değerlendirildiğinde, annelerin çocuklarına ilişkin internet ortamında bilgi ve fotoğraf paylaşmaya 0-2 yaş gibi çok erken bir dönemde başladıkları ve anneler \%85'e yakın oranda, çocukları henüz altı yaşına gelmeden onlarla ilgili bilgi ve fotoğraf paylaştıkları belirlenmiştir. Ayrıca annelerin büyük bir bölümü, sosyal medyada bilgi paylaşmayı yanlış ve suç olarak görmelerine rağmen bunu yapmaktadırlar. İlgili alan yazın incelendiğinde de ebeveynlerin yaşadığı bu ikilem Türkiye (Özaslan, Gültekin Akduman, Aydoğan, 2018b), Danimarka (Damkjaer, 2018) ve Estonya (Lipu ve Siibak, 2019) da yapılan araştırmalarda da vurgulanmıştır. Bu durumun en temel sebebi günümüzde ebeveynlerin kullandıkları akıllı telefonlar sayesinde, her ortam ve durumda çocuklarının fotoğraflarını kolaylıkla çekebilmeleri ve anında paylaşabilmeleridir (Wagner ve Gasche, 2018). Bu kolaylığın bir sonucu olarak da ebeveynlerin çocukları ilgili paylaşım oranları arttırmaktadir. 
İlginçtir ki, Anneler sosyal medyada çocuklarıyla ilgili fotoğraf ve bilgi paylaşma sıklığını nadir olarak yaptıklarını beyan etmişlerdir. İlgili literatürde annelerin profil hesapları incelendiğinde bu oranların daha yüksek olduğu belirlenmiştir. Örneğin, Almanya ve Avusturya da yapılan çalışmalarda katılımcıların çoğunluğun en az ayda bir paylaşım yaptığı belirlenmiştir (Wagner ve Gasche, 2018). Alan yazında farklı çalışmalar, paylaşımların daha sık yapıldığını göstermektedir. Maraşlı ve Ark. (2016) üç ay boyunca incelenen profillerde paylaşım oranın yüksek olduğunu ortaya koymuşlardır. Ebeveynlerin çocuklarıyla ilgili bilgi, fotoğraf paylaşımının içerik ve sıklı̆̆ının yüksek olduğu görülmüştür (Davis ve diğerleri, 2015). Bu çalışmada paylaşım sıklığı oranlarının düşük olması, verilerin doğrudan annelerin sosyal medya hesaplarının içeriklerinden alınmamasından ve annelerin beyanlarına bağlı olarak elde edilmesinden kaynaklı bir sınırlılıkla açıklanabilir. Ayrıca mevcut araştırmada, annelerin çocuklarıyla ilgili paylaşımları çoğunlukla Whatsapp uygulaması üzerinden yaptıkları belirlenmiştir. Watsapp/durum da paylaşılan bilgi ve fotoğrafların yalnızca kişilerin rehberinde olan ya da telefon numarasını bilen kişiler tarafindan görülebilmektedir. Bu özellik diğer sosyal medya hesaplarıyla kıyasladığında nispeten daha güvenli bir ortam sunmaktadır. Bu bulgular, farklı araştırma sonuçlarıyla (Davis, 2015; Maraşlı ve ark., 2016; Brosh, 2016; Wagner ve Gasche, 2018) paralellik göstermektedir. Yaygın kullanılmasına rağmen, Instagram ve Facebook sosyal paylaşım siteleri, Whatsapp/durumun uygulamasının çok gerisinde kalmıştır. Sosyal medya platform ve uygulamalanındaki yenilik ve değişiklikler sonraki araştırmalarda bu sıralamayı değiştirmesi muhtemeldir.

$\mathrm{Bu}$ araştırmada elde edilen sonuçlarda, çocuklarla ilgili sosyal medyada bilgi paylaşımının en fazla anneler tarafından yapıldığı göstermektedir. Bu sonuçlar benzer araştırma bulgularıyla da desteklenmektedir (Lazard ve ark.,2018; Moser, Chen ve Schoenebeck, 2017; Ammari ve ark. 2015; Davis ve diğerleri, 2015). Annelerden başka, en fazla paylaşım yapanlar diğer aile bireyleri (hala, teyze, büyük ebeveyn gibi) gelmektedir. Okul/öğretmen seçeneği en az işaretlenen seçenek konumundadır. Bu seçeneğin düşük olarak işaretlenmesinde $(\% 7,5)$ Milli Eğitim Bakanlığ1 Hukuk Hizmetleri Genel Müdürlügünün 07.03.2017 tarih ve 2975829 sayılı Okullarda Sosyal Medyanın Kullanılması konulu genelgesinde öğrencilere ait her türlü ses, görüntü ve videonun MEB personeli tarafından paylaşılmasının hukuka aykırı olduğu hatırlatılmasının rolünün olduğu söylenebilir.

Özel günlerdeki (doğum günü, diş partileri gibi) bilgi ve fotoğraflar sosyal medyada anneler tarafından en çok yapılan paylaşımlar ve okul da yapılan etkinlik, ürün, başarı, ödül vb yaşantılar ile tatil ve seyahat anıları sosyal medyada en çok yer verilen yaşantılar olarak öne çıkmıştır. Sonuçlar alan yazınla örtüşmektedir. Ebeveynlerin; diploma, sertifika gibi başarı belgeleri, doğum videosu, bebeklik fotoğrafları (Brosh, 2016), doğum günü, mezuniyet, yıl sonu gösterileri (Maraşlı ve 
ark.,2016), moda ve eğlence (Choi ve Lewallen, 2018) ve yeni kişilerle tanışma, giyim tarzları, spor (Ammari ve ark.,2015) yaşantıları paylaştıkları görülmektedir.

Araştırmanın ikinci sorusu değerlendirildiğinde annelerin yarısına yakını, çocuklarıyla ilgili paylaşım yapmalarına gerekçe olarak hatıra, anı biriktirmeyi sunmuşlardır. Bu gerekçeyi, paylaşılan fotoğrafların beğenilmesinden duydukları mutluluk ve başarılarını duyurmaktan keyif almak takip etmektedir. Sharenting ile ilgili yapılan çalışmalarda benzer gerekçelere vurgu yapılmaktadır. Bu gerekçeler, akraba ve tanıdıkların çocukları görmesi (Özaslan, Gültekin Akduman ve Aydoğan, 2018b), iyi ebeveyn olmaya çalışmak (Damkjaer, 2018), çocukların hobilere katılımıyla ilgili olumlu içerik paylaşarak iyi ebeveyn olarak algılanma (Moser, Chen ve Schoenebeck, 2017), çocuklarından gurur duyduklarını hissettirmek (Lazard ve ark., 2018) olarak sayılabilir. Araştırma sonuçları göstermektedir ki, anneler başkalarına uyum sağladıkları için paylaşım yapmayı kabul etmemekle birlikte, doğru bulmasalar da iyi, ilgili ebeveyn olarak algılanmak adına çocuklarıyla ilgili bilgi veya fotoğraf paylaşıyorlar.

Tüm veriler 1şığında bu araştırma sonuçları sosyal medyada çocukların fotoğraflarının paylaşılmasının anneler arasında yaygın bir davranış olduğu ortaya çıkmaktadır. Anneler tarafından yapılan bu paylaşımların çoğunluğunun çok erken (0-2 yaş) dönemde başladığ1 söylenebilir. Annelerin yarısına yakını (\%48.1) paylaşmayı doğru buldukları ve bu nedenle paylaştıklarını ifade ederken, bu orana yakın (\%36.7) bir grup annenin de doğru bulmadıkları halde paylaştıkları görülmektedir. Çok az sayıda annenin, yanlış bulup paylaşmadığı sonucu ortaya çıkmaktadır. En çok tercih edilen uygulamanın Whatsapp durum olduğu ve özel günlerin (doğum günü, diş partileri gibi) paylaşılan durum olarak öne çıktığ görülmektedir. Son olarak anneler daha çok hatıra biriktirmek amacıyla paylaşmaktadırlar. Bu sonuçlara bakıldığında erken çocukluk dönemi çocukları sharenting bağlamında ciddi risk altındalar. Bu dönemdeki çocukların paylaşımın içeriğinden haberdar olma, onay verme ve kendilerini bunun risklerinden korumaları olası değildir.

$\mathrm{Bu}$ araştırmada elde edilen bulgular 1şığında anne-baba ve araştırmacılara bazı öneriler sunulabilir. Bunlar; ebeveynler kendilerine ve çocuklarına ilişkin bilgi paylaştıkları sitelerin gizlilik politikalarını mutlaka bilmeli, çocuklarının kişisel bilgileri (TC kimlik no, doğum tarihi gibi) sosyal paylaşım ağlarında paylaşmamaya özen göstermelidir. Anne-babalar, çocuğun kişisel bilgilerini kamusal bir alanda paylaşmanın tehlikesini de göz önüne alarak davranabilirler. Anne-babalar paylaşım yaparken, bu paylaşımlarının çocuklarının bugün ve gelecekteki durumunu nasıl etkileyeceğini de göz önünde bulundurabilir. Çocuklarla ilgili özel ve mahrem bilgi paylaşımı yapan ebeveynler ve verileri izinsiz bir şekilde kullanan üçünü kişiler hakkında hukuki zeminde mücadele etmeyi 
sağlayacak somut düzenlemelerin yeterli olmadığ1 konusunda anneler uyarılabilir. Ebeveynlerin çocukları hakkındaki paylaşımlarının çevrimiçi gizlilik haklanı noktasında daha çok bilgiye ihtiyacı olduğundan hareketle (Steinberg, 2016; Steinberg, 2017), bu araştırmanın benzer sonucuna da dayanarak, özellikle çocuğu okul öncesi dönemde olan annelere sharenting konusunda seminerler verilebilir. $\mathrm{Bu}$ araştırmada çocuklarla ilgili paylaşımların, okul/ öğretmen ve diğer aile bireyleri tarafindan yapıldığından yola çıkarak bu eğitimler anne-babalar, öğretmenler ve diğer okul personelini kapsayacak şekilde genişletilebilir. Bu çalışma sharenting eylemini sınırlı yönüyle ele alan bir çalışmadır. Sonraki araştırmalar kavram farklı boyutlarıyla, çok yönlü ele alacak şekilde planlanabilir. Bu çalışmanın katılımcıları annelerdir, sonraki araştırmalar, anneler, babalar, diğer aile üyeleri, öğretmen ve okulun personelini de dahil eden sharenting olgusunun risklerini konu alacak şekilde planlanabilir.

\section{KAYNAKÇA}

Akdi, M. (2016). Ana-babanın çocuğun fotoğraf ve görüntülerinin sosyal medyada yayınlamasından doğan sorumluluğu. Marmara Üniversitesi Hukuk Fakültesi Hukuk. Arastırmalar Dergisi, 22(3), 123-144.

Allen, K. A., Ryan, T., Gray, D. L., McInerney, D. M., ve Waters, L. (2014). Social media use and social connectedness in adolescents: The positives and the potential pitfalls. The Educational and Developmental Psychologist, 31(1), 18-31.

Ammari, T., Kumar, P., Lampe, C., ve Schoenebeck, S. (2015, Nisan). Managing children's online identities: How parents decide what to disclose about their children online. Proceedings of the 33rd Annual ACM Conference on Human Factors in Computing Systems (ss. 1895-1904). SeulGüneykore.

Blum-Ross, A., ve Livingstone, S. (2017). "Sharenting," parent blogging, and the boundaries of the digital self. Popular Communication, 15(2), 110-125.

Brosch, A. (2016). When the child is born into the internet: Sharenting as a growing trend among parents on facebook. The New Educational Review, 43(1), 225-236.

Chazan, D. (2016). French parents 'could be jailed' forposting children's photos online. The Telegraph. 9 Mart 2019 tarihinde http://www.telegraph.co.uk/news/worldnews/europe/france/12179584/Frenchparents-could be-jailed-for-posting-childrens-photos-online.html adresinden erişildi.

Choi, G. Y., ve Lewallen, J. (2018). “Say Instagram, Kids!”: Examining sharenting and children's digital representations on instagram. Howard Journal of Communications, 29(2), 144-164.

Çimke, S., Gürkan, D. Y., ve Polat, S. Sosyal medyada çocuk hakkı ihlali: Sharenting. Güncel Pediatri, 16(2), 261-267. 
Damkjaer, M.S. (2018), "Sharenting= good parenting? Four parental approaches to sharenting on facebook", Digital Parenting, The International Clearinghouse on Children, Youth and Media at NORDICOM, 209-218.

Davidson-Wall, N. (2018, April). "Mum, seriously!” Sharenting the new social trend with no optout. In Paperpresented at the 9th Debating Communities and Social Networks 2018 OU A Conference. Online Konferans.

Davis M., Clark S.J., Singer D.C., Hale K., Matos-Moreno A., ve Kauffman A.D. (2015). Parents on social media: Likes and dislikes of sharenting, C.S. Mott Children's Hospital National Poll on Children's Health. 23(2).

DigitalTalks. (2018).Türkiye'de Her On 6-15 Yaş Arası Cocuktan 6'sı Akıllı Telefon Sabibi. 12 Haziran 2019 tarihinde https:/ / www.digitaltalks.org/2018/08/27/turkiyede-her-on-6-15-yas-arasicocuktan-6si-akilli-telefon-sahibi/ adresinden erişilmiştir.

Duggan, M., Lenhart, A., Lampe, C., ve Ellison, N.B. (2015). Parents and Social Media, Pew Research Center. 9 Mart 2019 tarihinde https://www.pewinternet.org/2015/07/16/parents-andsocial-media/ adresinden erişilmiştir.

Family Online Safety Institute (2015). Parents, Privacy \& Technology Use. 24 Nisan 2019 tarihinde https://www.fosi.org/policy-research/parents-privacy-technology-use/ adresinden erişilmiştir.

Gültekin, E. (2018). Çocuğun kişilik hakkının ana-baba tarafindan sosyal medya aracıllı̆̆ıyla ihlalinin hukuki görünümü. Cocuk ve Medeniyet Dergisi, 3(5), 103-143.

Kaya, G. ve Kaya, U. (2017). Bir ebeveyn pratiği olarak "sharenting”. Current Debates in Education. 19(26), 443-454.

Lazard, L., Locke, A., Dann, C., Capdevila, R., ve Roper, S. (2018). Sharenting: Why mothers post about their children on social media. The Conversation, 9.

Lipu, M., \& Siibak, A. (2019). 'Take it down!': Estonian parents' and pre-teens' opinions and experiences with sharenting. Media International Australia, 170(1), 57-67.

Livingstone, S., Blum-Ross, A., Pavlick, J., ve Ólafsson, K. (2018). In the digital home, how do parents support their children and who supports them? Parenting for a digital future: survey report 1 Parenting for a Digital Future. London: London School of Economics.

Maraşl1, M., Sühendan, E., Yllmaztürk, N. H., ve Cok, F. (2016). Parents' shares on social networking sites about their children: Sharenting. The Anthropologist, 24(2), 399-406.

Minkus, T., Liu, K., ve Ross, K. W. (2015, May). Children seen but not heard: When parents compromise children's online privacy. Proceedings of the 24th International Conference on World Wide Web (ss. 776-786). Cenevre-İsviçre

Moser, C., Chen, T., ve Schoenebeck, S. Y. (2017, May). Parents and children's preferences about parents sharing about children on social media. Proceedings of the 2017 CHI Conference on Human Factors in Computing Systems (ss. 5221-5225). ACM. 
Özaslan, H., Gültekin Akduman, G., Aydoğan, Y. (2018a, Ekim). Siber güvenlik: Sosyal paylaşım sitelerinde aile mahremiyetine iliskin bir inceleme. Uluslararası IV. Çocuk Gelişimi Kongresi: 50 Yılda Çocuk Gelişiminin İz Bırakan Yolculuğu, Hacettepe Üniversitesi, Ankara

Özaslan, H., Gültekin Akduman, G., Aydoğan, Y. (2018b, Ekim). Ailelerin, sosyal medyada çocuğun haklarna ve mahremiyetine ilișkein görüşleri. Uluslararası IV. Çocuk Gelișimi Kongresi: 50 Yılda Çocuk Gelişiminin İz Bırakan Yolculuğu, Hacettepe Üniversitesi, Ankara.

Sharenting. In: Collins Dictionary. 7 Mart 2019 tarihinde https://www.collinsdictionary.com/dictionary/english/sharenting adresinden erişilmiştir.

Steinberg, S. B. (2016). Sharenting: children's privacy in the age of social media. Emory LJ, 66, 839.

Steinberg, S. (2017, 17 Mayıs). Sharenting - in whose interests? Parenting for a digital future [Blog yazıs1]. $\quad$ Erişim adresi: https://blogs.1se.ac.uk/parenting4digitalfuture/2017/05/17/sharenting-in-whoseinterests/

Wagner, A., ve Gasche, L. A. (2018). Sharenting: Making decisions about other's privacy on social networking sites. Darmstadt Technical University, Department of Business Administration, Economics and Law, Institute for Business Studies (BWL). 977-988

We are social. (2019), The State of te Internet in 2019. 24 Şubat 2019 tarihinde https://wearesocial.com/blog/2019/01/digital-2019-global-internet-use-accelerates adresinden erişilmiştir. 